\title{
LUMBAR DISC PROTRUSIONS IN PREGNANCY
}

\author{
BY \\ J. E. A. O'CONNELL \\ From St. Bartholomew's Hospital, London
}

The occurence of paralysis of a lower limb of the mother after labour was first described at least 120 years ago (von Basedow, 1838). The condition is uncommon, Beattie (1933) reporting an incidence of less than 1 in 2,500 deliveries. This "maternal obstetrical palsy", as it has been named, has usually been considered to result from injury to the lumbosacral plexus occasioned by the foetal head or obstetric forceps during delivery in cases of disproportion. The hypothesis would seem to have sound foundations when paralysis follows a difficult labour and involves muscles supplied by one of the large nerve trunks passing through the true pelvis. However, doubts as to its adequacy in all cases have been expressed since the hypothesis was first put forward. Thus it is recorded that paralysis may follow an apparently normal labour and it may involve the quadriceps femoris muscle of which the nerve of supply, having no intrapelvic course, cannot be injured either by foetal head or obstetric forceps. In 1944 I described four cases of intervertebral disc protrusion developing during pregnancy or the puerperium and associated with a lower limb weakness of greater or less severity; it was suggested on the basis of these cases that protrusion of a lumbar disc was an aetiological factor in maternal obstetric paralysis. The purpose of the present communication is to review the matter in the light of subsequent experience.

In Table I it will be seen that of 1,100 consecutive

TABLE I

SEX INCIDENCE OF LUMBAR INTERVERTEBRAL DISC PROTRUSION IN A SURGICALLY PROVEN SERIES OF 1,100 CASES

\begin{tabular}{c|c}
\hline Male & $753(68 \cdot 5 \%)$ \\
Female & $347(31.5 \%)$ \\
\hline Total & $1,100(100 \%)$ \\
\hline
\end{tabular}

surgically proven and personally treated cases of lumbar disc protrusion, 347 were women, and an analysis of their case notes forms the basis of the observations which follow. The ages of the patients ranged from 16 to 60 years with the distribution in decades shown in Table II, over two-thirds of the
TABLE II

AGE RANGE OF FEMALE PATIENTS

\begin{tabular}{c|c}
\hline Age (years) & No. of Cases \\
\hline $11-20$ & $14(4 \%)$ \\
$21-30$ & $98(28 \%)$ \\
$31-40$ & $131(38 \%)$ \\
$41-50$ & $83(24 \%)$ \\
$51-60$ & $21(6 \%)$ \\
\hline Total & $347(100 \%)$ \\
\hline
\end{tabular}

TABLE III

INCIDENCE OF PREGNANCY

\begin{tabular}{l|c}
\hline & No. of Cases \\
& $179(51 \%)$ \\
$\begin{array}{l}\text { No pre more pregnancies } \\
\text { Unknown }\end{array}$ & $159(46 \%)$ \\
\hline Total & $9(3 \%)$ \\
\hline
\end{tabular}

group being in the child-bearing period of life. In Table III the incidence of pregnancy among the 347 patients is indicated, 179 , or a little more than half, having borne one or more children.

Symptoms of a lumbar disc protrusion occurred in pregnancy in 70 , that is, $39.1 \%$ of the patients who had been pregnant, and in 16 , or almost a quarter of these cases, symptoms occurred in two or more pregnancies (Table IV). In 53 of the 70

TABLE IV

FREOUENCY OF DEVELOPMENT DURING PREGNANCY OF SYMPTOMS OF LUMBAR DISC PROTRUSION

1. Symptoms in one or more pregnancies: 70 cases

$20.2 \%$ of the total group of 347 cases $39.1 \%$ of 179 patients who had been pregnant

2. Symptoms in 2 or more pregnancies: 16 cases

$23 \%$ of the 70 cases

3. Associated aetiological factor:

Pregnancy sole recognized factor : 58 cases

Pregnancy associated with other cause : 12 cases

70 cases

cases no symptoms suggestive of a disc protrusion had been present before those arising in pregnancy; in the remaining 17 cases pregnancy was associated with a recurrence or aggravation of previous low back pain and/or sciatic pain. In only 12 of the 
70 patients was there a history of a recognized back strain occurring before the onset of symptoms and frequently the relationship of the injury to the development of symptoms was not clearly defined.

In Table $\mathrm{V}$ the distribution of pain associated with disc protrusions in pregnancy is shown. In

TABLE V

DISTRIBUTION OF PAIN ASSOCIATED WITH DISC PROTRUSIONS IN PREGNANCY

A. Initial symptoms of protrusion arising in pregnancy in 53 cases

Low back pain alone .....14 cases in 5 in each of two pregnancies

Sciatic pain alone $\ldots \ldots \ldots 9$ cases in 2 in each of two pregnancies

Low back and sciatic pain 30 cases $\left\{\begin{array}{c}\text { in } 1 \text { in each of three } \\ \text { pregnancies } \\ \text { in } 5 \text { in each of two } \\ \text { pregnancies }\end{array}\right.$

B. Recurrence of aggravation of previously present symptoms in pregnancy in 17 cases

Low back pain .........4 4 cases

Sciatic pain added to pre-

existing back pain .... 5 cases

Low back and sciatic pain 8 cases

three-fourths of the group sciatic pain occurred with or without low back pain in addition; in one-fourth the pain was confined to the low back during pregnancy, crural pain developing at some later time. In Table VI the time of the onset of symptoms is indicated. These arose most commonly during pregnancy itself $(60 \%)$; in $11 \%$ they developed during labour and in $29 \%$ during the puerperium.

TABLE VI

TIME OF ONSET OF SYMPTOMS

\begin{tabular}{c|c}
\hline Time of Onset & No. of Cases \\
\hline During pregnancy & 42 \\
During labour & 8 \\
During puerperium & 20 \\
\hline Total & 70 \\
\hline
\end{tabular}

It is believed that these figures support the view that pregnancy in some way predisposes to the development of a lumbar disc protrusion. It is possible that postural stress during pregnancy and mechanical stress during labour may lead to injury of a lumbar intervertebral joint; further diminution of lumbar muscle tone in the puerperium may increase the risks of such injury from minor stress. A further possible factor, discussed in a previous paper (O'Connell, 1944), is a hormonal one. A secretion of the corpus luteum, relaxin, has been thought to be responsible for the increased mobility of the sacro-iliac and pubic symphyseal joints during pregnancy. It seems possible that this secretion might also induce changes in the ligamentous coverings of other joints, including the lumbar intervertebral ones, and that such changes might render these joints more vulnerable to stress.

Muscular weakness in the affected lower limb is a well-recognized complication of lumbar disc protrusions. At times, in spite of the presence of hypotonia and atrophy of the posterior crural muscles, there is no demonstrable paresis. More often a weakness of certain toe movements is demonstrable and in a proportion of cases a severe paresis or a paralysis of movement at the ankle and perhaps knee and hip joints occurs. In Table VII the incidence and severity of a defect of power in the whole group of 347 female patients in whom the presence of a lumbar disc protrusion has been surgically proven is shown. Such a defect was present to a greater or lesser extent in $69 \%$. It involved movements at joints proximal to the toes and was moderate or severe in degree in $19 \%$ of the whole group. Table VII also indicates the frequency and severity of loss of muscular power in 36 cases of disc protrusion occurring in pregnancy.

TABLE VII

INCIDENCE OF LOSS OF MUSCLE POWER

\begin{tabular}{l|r}
\hline & No. of Cases \\
In whole group of 347 cases & $106(31 \%)$ \\
No muscle weakness & $174(50 \%)$ \\
Minimal muscle weakness & $54(15 \%)$ \\
Moderate muscle weakness & $13(4 \%)$ \\
Severe muscle weakness & $347(100 \%)$ \\
\hline \multicolumn{1}{c|}{ Total } & \\
\hline In 36 cases in which pre-operative & \\
symptoms developed in pregnancy & $5(14 \%)$ \\
No muscle weakness & $9(25 \%)$ \\
Minimal muscle weakness & $3(8 \%)$ \\
Moderate muscle weakness & $36(100 \%)$ \\
Severe muscle weakness & \\
\hline \multicolumn{1}{c}{ Total } & \\
\hline
\end{tabular}

These 36 patients had symptoms of a protrusion arise in relation to pregnancy and persist to the time of examination; in the remaining 34 of the 70 patients in whom symptoms of a disc injury arose in pregnancy, a history of such symptoms was obtained but spontaneous recovery took place, the patient being later operated upon for a recurrence of symptoms not associated with pregnancy. A motor defect was present in $86 \%$ of the 36 cases in question and involved power at proximal joints in $33 \%$. These figures indicate that lower limb paresis occurs in association with the lumbar disc protrusions of pregnancy and suggest that it may be more common and more severe than is the case when protrusions occur in non-pregnant women.

In Table VIII significant features of the case histories of the three patients who developed the most severe motor defect are set out. In each of 
TABLE VIII

ANALYSIS OF RECORDS OF THREE PATIENTS WITH SEVERE DEFECT OF MUSCLE POWER

\begin{tabular}{|c|c|c|c|}
\hline & M.W. Aged 27 Years & D.R. Aged 32 Years & E.G. Aged 27 Years \\
\hline $\begin{array}{l}\text { Onset of pain } \\
\text { Weakness first noticed } \\
\text { Muscles affected }\end{array}$ & $\begin{array}{l}\text { Low back and sciatic pain } 2 \text { days } \\
\text { before labour } \\
\text { 7th day puerperium } \\
\text { Paralysis: dorsiflexion foot and } \\
\text { toes: eversion ankle } \\
\text { Severe paresis, remaining ankle } \\
\text { and toe movement } \\
\text { L.5 S.1; Wt. } 8.0 \mathrm{~g} \text {. } \\
\text { Pain relieved, some residual } \\
\text { weakness } 5 \text { years }\end{array}$ & $\begin{array}{l}\text { Low back: pregnancy, sciatic } \\
\text { 10th day puerperium } \\
\text { ? } \\
\text { Severe paresis: all ankle and toe } \\
\text { movement apart plantar flexion } \\
\text { ankle } \\
\text { L.4-5; Wt. } 4.8 \mathrm{~g} \text {. } \\
\text { Pain relieved, power recovered }\end{array}$ & $\begin{array}{l}\text { Sciatic: 7th day puerperium low } \\
\text { back; later } \\
\text { Two hours after labour } \\
\text { Severe paresis: toe and ankle } \\
\text { movement apart plantar flexion } \\
\text { Also knee flexion, hip extension } \\
\text { and abduction } \\
\text { L.5 S.1; Wt. } 1.8 \mathrm{~g} \text {. } \\
\text { Pain relieved, power improved } \\
\text { (2 years) }\end{array}$ \\
\hline
\end{tabular}

them the loss of power itself occasioned wellmarked disability. The findings in the nine patients who developed a weakness, less severe than in the previous group, yet of considerably greater severity than is usually encountered in cases of lumbar disc protrusion, are set out in Table IX. The time of onset of the muscular weakness in these 12 patients in whom it was either severe or moderately severe is of interest. In the three most severely affected

TABLE IX

ANALYSIS OF RECORDS OF NINE PATIENTS WITH MODERATELY SEVERE DEFECT OF MUSCLE POWER

\begin{tabular}{|c|c|}
\hline $\begin{array}{l}\text { Onset of pain } \\
\text { Onset of weakness } \\
\text { Movements affected }\end{array}$ & 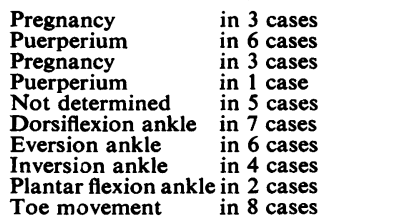 \\
\hline $\begin{array}{l}\text { Level of protrusion } \\
\text { Result }\end{array}$ & $\begin{array}{l}\text { L.4-5 } \\
\text { L.5 S.1 } \\
\text { Rapid recovery of power in all cases }\end{array}$ \\
\hline
\end{tabular}

patients it is known to have developed early in the puerperium in two and probably did also in the third patient. Of the nine patients with a limb weakness of moderate degree, three developed pain and loss of power in the early months of pregnancy, excision of the disc protrusion being followed by relief of symptoms and a subsequent normal labour. In the remaining six cases of the group pain developed early in the puerperium and in one of these it is known that paresis appeared at the same time. The other five were not examined until several months had elapsed after labour and therefore the time of onset of the muscular paresis remains uncertain. Thus in four patients the time of onset of the muscular paresis due to an intervertebral disc protrusion in pregnancy was similar to that of the paresis occasioned by injury to the lumbo-sacral plexus so that the former cause might be overlooked and the disability attributed to the latter one. A further reason for confusion between the aetiological factors lies in the distribution of muscle weakness. In
Tables VIII and IX it will be seen that the movements most commonly and most severely affected in this series of cases were dorsiflexion and eversion of the ankle joint, precisely the same as those reported in the literature as occurring after lumbosacral plexus injury in childbirth.

Review of this material suggests that, contrary to some published opinions (King, 1950), the association of pregnancy and a lumbar intervertebral disc protrusion is not uncommon. Indeed it is believed that the figures lend support to the view that pregnancy is an aetiological factor in the development of lumbar disc protrusions in women. Moreover, since such a protrusion may occur in the early puerperium and produce a severe lower limb paresis, the lesion must be regarded as an established cause of certain obstetric lumbo-sacral palsies. It has been stated that the differentiation of pareses due to plexus injury from those due to disc protrusions should present little difficulty (King, 1950). While this may frequently be the case, experience suggests that it is not invariably so. Clearly when paralysis and sensory loss develop with little or no associated pain and without spinal signs or evidence of tension in the roots of the sciatic nerve, the diagnosis is likely to be one of a plexus injury during labour. When, on the contrary, the neurological defect is associated with much pain and with well-marked spinal and tension signs, the diagnosis of a lumbar disc protrusion is the likely one. However, pain is recorded as having been severe in some cases considered to be examples of plexus injury, and it is a common experience that when a lumbar disc protrusion causes severe nerve injury and paralysis, pain due to it may greatly diminish. As an illustration of the diagnostic difficulty that may arise, the paper of Tillman (1935) may be mentioned. This author gives the records of eight patients in whom he believed plexus injury had occurred. In six of these pain was a major feature and developed either before labour (one case) or during the first 10 days of the puerperium. In two of the six patients no actual weakness is described and it appears that pain was the major cause of disability. Although in 
the remaining four patients well-marked muscular weakness was present, pain was a persistent feature, and it seems possible that a disc protrusion rather than a plexus injury had occurred in some of the cases of the series. In several personal cases no firm conclusion as to the cause of the obstetric lumbo-sacral palsy has been reached. Among these was a patient who developed a clear-cut picture of a lumbar disc protrusion during one pregnancy, recovered rapidly after delivery, and some years later was seen with a severe paresis of a lower limb after forceps delivery of another child. It is at least possible that the pain in one pregnancy and the paralysis after the other were occasioned by the same cause, a lumbar disc protrusion.

\section{Summary}

The records of 347 consecutive women with surgically proven lumbar intervertebral disc protrusions have been reviewed.

Of those patients in the series who had borne one or more children, $39 \%$ developed symptoms of a disc protrusion in pregnancy or the puerperium. This indicates that pregnancy is an aetiological factor in the development of lumbar disc protrusions in women.

In 12 of the 70 patients developing symptoms of a disc protrusion in pregnancy a lower limb paresis of severe or moderate degree occurred and involved the ankle and occasionally the knee and hip joints. In a quarter of these patients the paresis developed in the early puerperium.

The possibility of a lumbar disc protrusion being responsible for a maternal obstetrical palsy should be considered before the defect is assumed to result from lumbo-sacral plexus injury.

\section{REFERENCES}

Basedow, von (1838). Wschr. ges. Heilk., p. 636. Beattie, J. (1933) St. Barts Hosp. Rep., 66, 171. King, A. B. (1950). Arch. Neurol. Psychiat. (Chicago), 63, 611. O'Connell, J. E. A. (1944). Surg. Gynec. Obstet., 79, 374.
Tillman, A. J. B. (1935). Amer. J. Obstet. Gynec., 29, 660. 